\title{
The Housing Careers of Older Canadians: An Inves- tigation Using Cycle 16 of the General Social Survey
}

\author{
Michael Haan \\ University of Alberta \\ mhaan@ualberta.ca \\ Thomas Perks \\ University of Lethbridge \\ thomas.perks@uleth.ca
}

\begin{abstract}
In this paper we use the Aging and Social Support Survey (GSS16) and the theoretical conception of a 'housing career' to identify the correlates of housing tenure (rent vs. own) among Canadians age 45 and over. We draw on primarily US literature to isolate three general explanatory clusters (social support, health, and economic characteristics). Based on analyses using logistic regression, the results indicate that the majority of variation in housing tenure exists due to standard demographic and household characteristics. In fact, of the three focal explanatory clusters, only social support characteristics significantly enhance model fit beyond the baseline model, suggesting that the housing tenure of older Canadians hinges heavily on fairly standard characteristics.
\end{abstract} Keywords: Housing career; housing tenure; older adults

\section{Résumé}

Dans cet article, nous nous sommes servis de l'enquête "Vieillissement et soutien social » (ESG16) et de la théorie du cycle de vie du logement pour identifier les corrélats des modes d'occupation (location vs. propriétariat) chez les canadiens âgés de 45 ans et plus. Nous avons principalement puisé la littérature des États-Unis pour isoler trois groupes explicatifs généraux (caractéristiques: de support social, de santé, et économiques). Les résultats, basés sur des analyses de régression logistique, indiquent que la majorité des variations dans les modes d'occupation peuvent être attribuées à des caractéristiques démographiques et économiques de base. En effet, des trois groupes explicatifs focaux, ce sont seulement les caractéristiques de support social qui ont fait monter l'ajustement du modèle en delà du modèle de base, ce qui suggère que les modes d'occupation des logements pour les canadiens d'un certain âge dépend beaucoup des caractéristiques de base. Mots clés: Cycle de vie du logement, modes d'occupation de logements, adultes âgés 


\section{Introduction}

Over the next 20 years, the baby boomers, Canada's largest-ever age cohort (Beaujot, 2004), will begin to retire. It is estimated that this will result in the number of people of retirement age increasing from 4.3 million in 2006 to about 8 million in 2026, comprising roughly $21.2 \%$ of Canada's total population (Statistics Canada, 2007). According to the Canada Housing and Mortgage Corporation (2001), such a significant change to Canada's demographic landscape is likely to have a major impact on housing in Canada. This makes information on the housing of older Canadians, both now and in the future, of considerable interest to public and private housing agencies.

Although research on many aspects of housing and population aging is underway (Cheal, 2000; Légaré, 1998; Lin, 2005; Schellenberg, 2004; Wister, 2005), no studies yet include a detailed analysis of the factors that lead to a change in housing tenure status (rent vs. own) among older Canadians. Most studies look at earlier phases of the housing career (Balakrishnan and Wu, 1992; Haan, 2005b; forthcoming; Ray and Moore, 1991; Skaburskis, 1997). To address this deficiency, we use logistic regression techniques and the 2002 Aging and Social Support Survey (GSS16) to isolate the determinants of housing tenure among Canadians age 45 and over. ${ }^{1}$ Using cross-sectional data, we take an exploratory look at how social support, health, and economic characteristics affect the tenure characteristics of older Canadians, while controlling for age, education, immigrant status, retirement status, sex, and geographical characteristics. ${ }^{2}$

In the section below, a fuller theoretical context for understanding housing tenure across the life course is provided by introducing the concepts of housing career and median housing consumer, followed by a review of relevant literature and research findings. From this literature, three primary areas (social support, health, and economic characteristics) emerge as primary candidates for shaping housing tenure in the later years.

\section{Literature Review}

\subsection{Housing Careers and the Median Housing Consumer}

Typically, most housing research relies on a microeconomic model of consumer choice for theoretical guidance, where "median housing consumers" make decisions based on their needs, preferences, and financial resources (Alba and Logan, 1992;

1. A limitation of this study is its use of the General Social Survey Cycle 16; it is, therefore, impossible to identify individuals living in publicly funded institutions, although roughly $7 \%$ of those over age 65 do so (Statistics Canada, 2006).

2. Several shorthand terms are used in this paper. "Older Canadians" is used in places to refer to people over the age of 45 , and is not meant to label these people as old or elderly. 
Flippen, 2001). Since these decisions are both sequential and contingent on life circumstances, people have "housing careers," much as they have employment and family careers (Mulder, 1993). Like these other careers, a housing career casts life as a series of changes in states, each affecting needs and preferences. A basic idealtype housing career (paraphrased from Foote et al., 1960, but reiterated in Murdie et al., 1999, and Haan, 2005b) might as a minimum contain the following phases: (1) pre-child, (2) childbearing (3) child-rearing and launching, (4) post-child, and (5) later life.

People in their pre-child phase are typically younger, and must contend with more precarious employment prospects, leading them to be cautious in their spending (Nagatani, 1972). Individuals either live with their parents or in rental accommodations. As income and employment stabilize, individuals - or possibly, by now, families - move into the second phase of the housing career, and think more seriously about previously unimportant issues like neighbourhood quality, proximity to certain amenities, etc., possibly prompting them to move into an owner-occupied dwelling. Families continue to shift their preferences several times as they pass through these housing career phases, although they are not expected to return to renting until later life, when they forfeit their housing equity to gain access to constant care. ${ }^{3}$

Admittedly, the concept of a housing career, at least as articulated above, is somewhat dated. In 1960, when Foote and colleagues introduced the housing career and the median housing consumer, it consisted of a husband and wife, married at age 23 and 20, respectively, with 2 or 3 children born when the husband was between 25-30 years old (Foote et al., 1960:97). Presumably, the male was the breadwinner, the couple remained married for life, and neither husband nor wife had any physical or health limitations. Little theoretical space was made for changes in health, social support, or economic status, even though there appears to have been a significant movement towards the individualization of the life course for many Canadians (Ravanera, Rajulton, and Burch, 1998).

Changes to the housing career since it was first conceptualized in the 1960s are particularly evident in its later stages. Consequently, the theoretical utility of an ideal-type housing career could be waning, and it may be necessary to talk about a new housing career (or careers) for older Canadians. This is discussed more fully in the section below.

\subsection{New Housing Careers}

Housing careers appear to be both lengthening and diversifying, due in no small part to changes in the characteristics of older Canadians. Perhaps the most important fac-

3. This is obviously a "straw man" version of the housing career, and has been criticized heavily for its blindness to the unique nature of housing as an investment good. It is presented here only as a baseline model of housing consumption, and departures are expected. The argument here is that careers are lengthening and diversifying, due at least in part to changes among Canadians age 45 and over. 
tor behind these changes is that people in Canada are living longer today than ever before (between 1991 and 2003 alone, life expectancy at the age of 65 in Canada increased by 1.2 years [Canada Mortgage and Housing Corporation, 1992; Schellenberg, 2004]), pointing to an upward swing in the vitality of older Canadians. As this affects the housing market, older adults today are more likely to remain in their owner-occupied dwellings than they were in the past. As evidence of this, consider that between 1981 and 2001 home ownership rates for those 65 and over increased from about 62\% to nearly 75\% (National Advisory Council on Aging, 2006).

A second factor related to changing careers is the diversification of retirement plans. According to a recent study by Schellenberg (2004), 22\% of nonretired people aged 45 to 59 said they plan to retire before age 60 , while comparable proportions said they plan to retire between 60 and $64(22 \%)$ or at $65(23 \%)$. Only $3 \%$ said they plan on retiring after 65 . Of these numbers, what is perhaps most surprising is that the remaining $31 \%$ said either that they don't know when they plan to retire, or that they do not intend to retire at all. This reluctance could be seen as a financial necessity - that is, that seniors have too much debt to retire - but this seems unlikely, since the National Advisory Council on Aging reports that $83 \%$ of senior households who owned their home were without a mortgage in $2001 .{ }^{4}$ Also, older Canadians are much healthier and wealthier than their predecessors, and their labour market participation rates continue to rise (Schellenberg, Turcotte, and Ram, 2005). Together, these factors suggest that the need to move out of owner-occupied housing has declined (Crossley and Ostrovsky, 2003; Foot and Stoffman, 1996).

Finally, the percentage of older Canadians living alone has been increasing steadily, as has the number of individuals living with unrelated persons (Légaré, 1998; National Advisory Council on Aging, 2006). Among these people, a significant percentage is at risk of housing affordability problems, health problems, and social isolation. In 2001, among seniors living alone, $40 \%$ of seniors were below the lowincome cut-off (LICO), and 38\% reported affordability problems (National Advisory Council on Aging, 2006). For many, these changes may limit their ability to stay in an owner-occupied dwelling, and possibly speed up their transition into tenancy.

To summarize, it appears as though changes in the housing careers of older Canadians are underway, and given the projected increase in the number of seniors in the coming years, it is important that we deepen our understanding of the factors that lead older Canadians in different residential directions. More succinctly, given the high home ownership rates, coupled with the theoretical expectation of a reversion to tenancy in the latter phases of the housing career, this study will look at the factors that predict an individual not owning his/her dwelling. This will be achieved by, first of all, elaborating upon the characteristics of older adults that have been shown in (largely American) existing research to spark the transition out of owner-occupied housing and into alternative housing options, followed by a multivariate analysis of the cross-sectional 2002 Aging and Social Support Survey.

4. This proportion is much higher than nonsenior households (33\%). 


\subsection{Some Recent Social, Health, and Economic Trends among Older Can- adians}

As mentioned above, older Canadians today have changed in many respects. On the positive side, they are healthier and wealthier than ever before; a potential negative is that their social support network has probably shrunk. In spite of this, little research has been done on how these changes will affect housing tenure among older Canadians. Therefore, in the literature review that follows, we draw on primarily US research examining the dwelling choices of older adults to help guide our analysis. Our detailed review of literature suggests that there are three primary "clusters" of variables that may predict housing tenure status among older residents. These clusters can be divided into social support, health, and economic characteristics, and are discussed more fully below.

\subsubsection{Social support}

Looking at research on housing, it seems that one of the greatest predictors of a change in dwelling in the later phases of the housing career is the breadth and depth of social support networks (Breeze, Sloggett, and Fletcher, 1999; Hays, 2002). At present in the United States, approximately $54 \%$ of the older population lives with a spouse, $31 \%$ live alone, $13 \%$ live with relatives other than a spouse, and $2 \%$ live with non-relatives (Pynoos and Golant, 1996).

Among these people, 3/4 own their homes (United States Department of Housing and Urban Development Office of Policy Development and Research, 1999), mostly without constant care, and the remaining $25 \%$ are divided among a plurality of residential options (including retirement communities with and without constant care, multiunit structures, etc.). These results point to a relative homogeneity in status (roughly $3 / 4$ of all older Americans occupy the same dwelling type), but it is important to note that what variation does exist across categories is closely tied to social support (Breeze, Sloggett, and Fletcher, 1999). Aging without a partner - as $30-40 \%$ of US baby boomers are expected to do (Easterlin, Schaeffer, and Macunovich, 1993) - losing that partner, or anyone else in the network (a sibling, or changes in the marital status or location of children), are all factors that lead a person out of an owner-occupied residence and into an alternative dwelling type.

US research suggests that it is not only the presence of a support network that is important, but also the capacity of that network to care for an individual. Among married couples in the past, for example, there was often a significant age gap between husbands and wives (husbands were usually older), and it was fairly commonplace for one partner to care for the other post-retirement (Lakdawalla and Schoeni, 2003). Today, however, age gaps between partners are shrinking, both in Canada and the United States, suggesting that the "caretaker spouse" model of the past may become less prevalent over time. If this is true, the age gap between partners should be a salient predictor of housing tenure, with couples that are the same approximate 
age being less likely to own than in situations where an individual has a younger caretaker spouse. Similarly, individuals with an older spouse might be expected to be about as likely as similarly aged couples to rent (or slightly less likely, given their additional responsibilities).

With declines in fertility rates, the number of children a person has to care for them is also shrinking. At the same time, however, increases in longevity and the relatively high fertility rates of the past suggest that the number of siblings will remain relatively high for older Canadians, thereby expanding an individual's social support network. Finally, although fertility rates are declining, so too are rates of childlessness (Tomassini et al., 2004), which might lead to fewer people with anyone whatsoever to care for them.

To summarize the research above, social support characteristics (the presence of a partner, children, or siblings, and the age gap between couples) are often found to be among the strongest predictors of older Americans' choice of dwelling (Andersen et al., 1998; Branch and Jette, 1982; Breeze, Sloggett, and Fletcher, 1999). Consequently, we may expect to find similar trends among older Canadians. In fact, research on housing in Canada shows a significant difference between people in collective dwellings, such as nursing homes, and those in private dwellings: the latter are more likely to have a partner present (Smith, 1996). We see similar trends in Canada with respect to couples having fewer children (Devereaux, 1990), and evidence of a diminishing age difference between partners (Wu, 1998). Therefore, we expect that the presence of a partner, sibling, and/or children will positively predict an individual's ability to remain a home owner, whereas either a positive age gap between couples (which is coded to mean that a person's spouse is older than they are), or a small age gap, will reduce an individual's ability to remain a homeowner, net of other characteristics.

\subsubsection{Health status}

The second area of interest for this project is health status. One of the assumptions of the ideal-type housing career is that it makes little room for health problems or physical limitations, except perhaps at the last stage of the housing career. As individuals age, the expectation is that they will have to forfeit their housing equity so that they can afford access to constant care. Unfortunately, research on housing and health in Canada is very limited (Dunn et al., 2006). Therefore, we again turn to primarily US research to anticipate what we might see in Canada.

US research seems to support the notion that as individuals progress through the latter stages of the housing career they become more likely to forfeit their housing, with a large body of literature confirming that declines in health or physical status trigger a change in residential status (Andersen et al., 1998; Branch and Jette, 1982; Breeze, Sloggett, and Fletcher, 1999; Hays and George, 2002; Quadagno, 1980). Given that roughly $3 / 4$ of these people are homeowners, in many cases this probably entails a shift out of home ownership. Similar results in Canada highlight the importance of health status as a predisposing factor of institutionalization (Trottier 
et al., 2000). The strong relationship between deteriorating health or physical status and dwelling change suggests that ongoing good health will have the opposite effect. That is to say, we expect to see that those who are in good health and are physically active will be most likely to be in a dwelling that they own.

\subsubsection{Economic characteristics and labour force status}

The third area of interest is economic status. Housing is typically the single largest asset most individuals have upon retirement (Alba and Logan, 1992; Myers and Lee, 1998), suggesting that individuals may need to liquidate this wealth source as they age (Crossley and Ostrovsky, 2003), unless they have enough resources to sustain both themselves and their dwelling. The necessity to liquidate can, of course, be delayed to some extent by remaining in the labour force longer - something Canadians are often now likely to do (Schellenberg, 2004) - but the basic expectation remains.

Much like the other two explanatory clusters, wealth and employment profiles are shifting for those 45 and over. Turning once again to the United States, it has been reported that each successive cohort of households has higher levels of education and financial resources, which in turn increases the likelihood of residential independence (Tomassini et al., 2004). Labour force participation rates continue to rise, which serves as an attestation of the ongoing health and vitality of older Americans and the desire and/or necessity to retain at least some attachment to the labour market. These trends towards greater economic independence among older adults have also been documented in Canada (Schellenberg, 2004). Given the high priority placed on privacy and individual autonomy in both Canada and the United States, economic characteristics and labour force participation should both weigh heavily on housing tenure, so that ongoing economic independence will be negatively associated with tenancy.

\section{Hypotheses}

To summarize the discussion above, there are at least three relevant expectations guiding the analysis. We expect to find that:

a. The stronger the social support network, the lower the risk of tenancy.

b. The better the health and the higher levels of physical activity, the lower the risk of tenancy.

c. The greater the wealth and/or economic independence, the lower the risk of tenancy.

\section{Methodological Approach}

\subsection{Data and Sample Restrictions}

Data for this project are taken from Statistics Canada's cross sectional 2002 General Social Survey (GSS16), available at the Edmonton Research Data Centre. The target 
population for the GSS16 was all persons 45 years of age and over residing in Canada, excluding residents of Nunavut, the Yukon, and Northwest Territories, residents of Indian Reserves, members of the Canadian Armed Forces, and full-time residents of institutions. Computer assisted telephone interviewing (CATI) was used to select respondents $(\mathrm{N}=24,855)$. (For more information on the GSS16, see Statistics Canada, 2002)

Our working sample for the analyses is restricted to nonproxy respondents with valid values for all variables used in the analysis $(\mathrm{N}=13,608)$.

\subsection{Estimation Technique and Focal Outcome}

The analytical centerpiece of this project is binomial logit regression. This procedure is appropriate for collectively assessing the effects of either categorical or continuous predictor variables on an outcome variable with two categories, while simultaneously controlling for other variables. Logit or logistic regression yields odds ratios, which are the exponentiated values of the regression coefficients.

The outcome of interest is a dichotomous variable, set to 1 if a person does not own their home, and 0 if they do. Admittedly, this is different from most home ownership research in Canada (Crossley and Ostrovsky, 2003; Haan, 2005a; 2007; Ray and Moore, 1991; Skaburskis, 1996; 1997), which focuses on the transition into home ownership (thereby coding ownership as 1 and tenancy as 0 ). Our decision to reverse the order of the dependent variable stems from our primary interest in determining the factors that are correlated with an individual not owning his or her accommodations. This focus models the median housing consumer's transition into the final phases of his/her housing career, part of which entails a reversion to tenancy.

As is always the case in secondary data analysis, we have no control over the questions that were asked in the survey. Ideally, we would have obtained more detail on the types of dwellings older adults choose to live in, including information on public retirement institutions. Additionally, it would be good to know that a person who is renting in our data has actually made the move out of ownership, rather than having been a renter throughout their adult lives. Obviously, this task would be better completed with longitudinal data, something which does not exist at present in Canada. On the plus side, however, the data are from a large, nationally representative sample, allowing us to generalize our findings to the older Canadian population more generally. Also, the data provide rich information on a number of social background characteristics that have been found to predict dwelling-type choice of older adults in the United States.

\subsection{Focal Predictors}

With our three hypotheses in mind, we incorporate three main explanatory variable clusters, as well as numerous other controls, into our analysis. These variables are described below. 


\subsubsection{Social support characteristics}

Four variables are used to assess levels of social support. Presence of partner is a dichotomous variable distinguishing respondents who do not have a spouse or partner living with them in the household (0) from those who do (1). Age difference between partners is coded in years, with a positive number indicating that the respondent's spouse/partner is older than they are, and a negative number referring to the opposite, with zero indicating there was no age difference. ${ }^{5}$ Number of children is a continuous variable measured in real numbers, based on questions asking respondents how many daughters or sons they have raised that are still living. Number of siblings, also a continuous variable, is based on questions asking respondents how many brothers or sisters they have that are still living. Ideally, we would be able to assess whether children or siblings live in the same area as the respondent, and are therefore able to take care of a respondent. Unfortunately, these data are not on the GSS file.

\begin{tabular}{l} 
Table 1: Selected Social Support Characteristics of Canadians \\
Age 45 and Over, 2002 General Social Survey \\
\hline
\end{tabular}

To give a better idea of the social support characteristics of the GSS sample, consider Table 1 above. We can see that the percentage of respondents with a partner is fairly stable up to age $65-74$, at which point a decline begins to emerge, so that only $44.5 \%$ of all respondents aged 75 and older have a partner present. As might be expected, the mean age difference between partners rises across age cohorts (probably reflecting the historical practice in Canada of men being older than women). Average number of children increases across age cohorts, reflecting declines in birth rates across cohorts, whereas the number of siblings operates in the opposite direction.

\subsubsection{Health characteristics}

Three variables are used to assess the health status of respondents. First, the Health Utility Index (HUI) is a health status measure designed to assess an individual's overall health based on eight attributes: vision, hearing, speech, mobility, dexterity, cognition, emotion, and pain and discomfort. The index defines scores of 1.00 as perfect health and scores of 0.00 as "death." ${ }^{6}$ Responses to the question, "During the past

5. So as not to lose a large percentage of respondents who do not have a partner present, the age difference between partners for respondents without a partner is set to zero. The addition of the dichotomous partner/no partner variable compensates for bias due to this substitution procedure.

6. For more information on the HUI, see Roberge, Berthelot, and Wolfson (1995). 
month, did you often (0), sometimes or rarely (1) or never (2) exercise or participate in sports, such as golf, swimming or curling?" are used to assess an individual's recent level of physical activity. For analytical purposes, this variable is made into a series of dummy variables ("often active" is the reference category). Self-rated health assessment is also included, and is expected to tap into an individual's perception of their health. Like the physical activity variable, this is represented by a series of dummy variables ("poor health" is the reference category).

Although Canada's seniors today are widely expected to be the healthiest, longest living generation ever (Martel and Bélanger, 2002; National Advisory Council on Aging, 2006), there still appears to be deterioration in health and physical activity levels as an individual ages (Table 2).

Notice that these Health Utility Index and physical activity characteristics do not neatly coincide with self-rated health information. Although fewer in the oldest cohort believe that they are in excellent health, over one-third of individuals over the age 75 , for example, still believe that they are in very good health, an almost identical rate to all other age groups.

\begin{tabular}{lrrrr}
\multicolumn{5}{l}{$\begin{array}{l}\text { Table 2: Selected Health and Physical Activity Characteristics } \\
\text { of Canadians Age } \mathbf{4 5} \text { and Over, } \\
\text { 2002 General Social Survey }\end{array}$} \\
\hline & \multicolumn{4}{c}{ Age Groups } \\
\cline { 2 - 5 } Characteristics & $45-54$ & $55-64$ & $65-74$ & $75+$ \\
\cline { 2 - 5 } Health Utility Index, mean & .88 & .84 & .83 & .75 \\
Always active, \% & $\mathbf{3 4 . 6 5}$ & $\mathbf{3 2 . 7 0}$ & $\mathbf{3 3 . 8 1}$ & $\mathbf{2 4 . 5 4}$ \\
Sometimes active & 22.00 & 14.71 & 11.08 & 9.68 \\
Never active & 43.35 & 52.59 & 55.11 & 65.78 \\
Poor health, \% & $\mathbf{1 . 6 0}$ & $\mathbf{3 . 0 0}$ & $\mathbf{1 . 8 5}$ & $\mathbf{1 . 7 8}$ \\
Fair health & 5.41 & 8.07 & 8.51 & 12.00 \\
Good health & 21.99 & 21.85 & 23.69 & 31.26 \\
Very good health & 36.62 & 34.49 & 36.50 & 35.33 \\
Excellent health & 34.38 & 32.59 & 29.45 & 19.63 \\
Number of Observations & 4061 & 3747 \\
\hline Note: Reference group for multivariate analysis denoted in bold & 3262 & 2538 \\
\hline
\end{tabular}

\subsubsection{Economic characteristics}

Five variables are used to assess the economic well-being and labour force status of respondents. Income (logged) is based on the question, "What is your best estimate of your total personal income, before deductions, from all sources during the past 12 months?" "Employment status is determined based on a question asking respondents how many hours per week they usually worked at a job or business. The variable is coded as (0) not working; (1) part-time (less than 30 hours per week); and (2) fulltime (30 or more hours per week). For analytical purposes, this variable is entered as

7. As is well-known, GSS income data are rather spotty, and not missing at random. 
a vector of dummy variables (not working is the reference category). We also include retirement status and years since retired (logged) as predictors of dwelling-type.

Before proceeding, it is necessary to comment on our definition of retirement. Analysts face a number of methodological issues when attempting to define retirement status. Most importantly, retirement means different things to different people. For some, retirement means complete withdrawal from the labour force, while for others it entails remaining partly or even fully active in the labour market (Bowlby, 2007). For the purposes of our analyses, we utilize a broad definition of retirement in order to capture respondents who report being retired and have a) disengaged from the workforce entirely; b) scaled back the number of hours that they work; or c) changed jobs and taken a noticeable drop in earnings. Retirement status is derived from several questions from the survey. First, individuals who said that their "main activity" during the past 12 months was "retired" are immediately identified as a retiree. Subsequently, individuals who do not identify their main activity as retired are asked "Have you ever retired?" Those who said "yes" to this question are also identified as retirees. Finally, individuals who say that they have never retired are asked follow-up questions that probe the issue in considerable detail, and again, individuals who responded positively to the follow-up questions are identified as retirees. Given the ambiguity around the term, we believe this definition is a reasonable one, since in some cases retirement means that individuals may still be working but are not working as hard as they once did. Research using this definition has recently been published by Statistics Canada (see Schellenberg, Turcotte, and Ram, 2005).

As might be expected, economic and labour market participation rates diminish with age (Table 3). Income declines with age, as does the propensity to work, either part-time or full-time, although it seems that a small fraction of respondents do remain tied to the labour market beyond age 75. Retirement rates and the mean logged number of years since retired increases with age, although it is curious that only $78 \%$ of those above age 75 identify as retired.

\begin{tabular}{lrrrr} 
Table 3: Selected Economic and Labour Market Characteristics \\
of Canadians Age $\mathbf{4 5}$ and Over, 2002 General Social Survey \\
\hline \multicolumn{5}{c}{ Age Groups } \\
\cline { 2 - 5 } Characteristics & $45-54$ & $55-64$ & $65-74$ & $75+$ \\
\cline { 2 - 5 } Income (logged), mean & 10.46 & 10.13 & 9.88 & 9.88 \\
Does not work, \% & $\mathbf{6 . 8 9}$ & $\mathbf{3 4 . 6 4}$ & $\mathbf{8 5 . 8 8}$ & $\mathbf{9 7 . 2 5}$ \\
Works part-time & 9.03 & 10.02 & 4.86 & .98 \\
Works full-time & 84.08 & 55.34 & 9.26 & 1.77 \\
Retired, \% & $\mathbf{8 . 2 0}$ & $\mathbf{3 8 . 7 9}$ & $\mathbf{8 1 . 0 8}$ & $\mathbf{7 8 . 1 3}$ \\
Years since Retirement (logged), mean & .13 & .57 & 1.59 & 2.07 \\
Number of Observations & 4061 & 3747 & 3262 & 2538 \\
\hline
\end{tabular}

Note: Reference group for multivariate analysis denoted in bold 


\subsubsection{Other characteristics}

In addition to the characteristics mentioned above, it is necessary to control for the effects of several other sociodemographic variables. Age is recoded into 10-year age categories: $45-54,55-64,65-74$, and $75+(45-54$ is the reference category). Sex is coded as male (0) and female (1). Immigrant status is derived from the question "In what year did you first come to Canada to live permanently?" and is coded into native-born (0), immigrated prior to 1990 (1), and immigrated during or after 1990 (2) (native-born is the reference category). Area of residence is coded into urban (0) and rural (1), according to Statistic Canada's rural-urban definition. ${ }^{8}$ Province of residence is a categorical variable, with Ontario treated as the reference category. Education is coded into 5 categories: university graduate (the reference category), college graduate, some university/college, high school, and less than high school.

Looking at the overall sample characteristics (Table 4), several trends can be noted. First, education bears a fairly strong relationship with age. Notably, completion of elementary school only is more prevalent among older Canadians, whereas younger members of the sample are much more likely to have a college or university diploma. Possibly reflecting differences in life expectancy, there are more females at higher ages. Across the sample, between $20-25 \%$ of all respondents were not born in Canada, and roughly a fifth are rural. Neither these variables nor the geographic characteristics vary dramatically with age. In fact, the only other variable for which age matters is with percent renter, the dependent variable. Although there is little difference between 45-54 and 55-64, after this point a decreasing share of the sample occupies an owned dwelling. ${ }^{9}$

To identify the independent impact of each of the above variable clusters while controlling for other, more standard, characteristics, requires logistic regression analysis, which we undertake in the section below.

\section{Multivariate Results}

The results of the logistic regression analyses are presented in Table 5. For the analysis, the variables are entered in blocks to correspond to our three research hypotheses noted above. In Model 1, the odds ratios for the sociodemographic control variables (Table 4) only are estimated. In Models 2, 3, and 4, in addition to the controls, the effects of the social support (Table 1), health status (Table 2), and economic and labour force variables (Table 3), respectively, are estimated. In the final model, Model 5, all of the above variables appear simultaneously.

8. Statistics Canada defines urban areas as having a minimum population of 1,000 people and a population density of at least 400 people per square kilometer, based on the 2001 census. All areas outside urban areas were considered rural.

9. It would be interesting to determine what happens to these people, but unfortunately the General Social Survey contains limited information on dwelling type beyond that which we include here. 
Table 4: Other Selected Characteristics of Canadians Age 45 and Over, 2002 General Social Survey

\begin{tabular}{|c|c|c|c|c|}
\hline \multirow[b]{2}{*}{ Characteristics } & \multicolumn{4}{|c|}{ Age groups } \\
\hline & $45-54$ & $55-64$ & $65-74$ & $75+$ \\
\hline University \% & 25.04 & 21.11 & 13.72 & 13.30 \\
\hline College & 29.92 & 24.75 & 19.55 & 16.27 \\
\hline Some univ/college & 14.97 & 13.59 & 12.54 & 12.29 \\
\hline Highschool & 16.78 & 14.99 & 14.10 & 11.59 \\
\hline Elementary & 13.29 & 25.56 & 40.09 & 46.55 \\
\hline Female, \% & 46.67 & 46.68 & 50.44 & 58.96 \\
\hline Canadian-born \% & 79.96 & 76.22 & 75.75 & 79.12 \\
\hline Immigrated pre-1990 & 16.19 & 22.25 & 23.57 & 20.53 \\
\hline Immigrated post-1990 & 3.85 & 1.53 & 0.68 & 0.35 \\
\hline Rural, \% & 20.94 & 22.82 & 21.10 & 17.15 \\
\hline Ontario \% & 35.41 & 37.69 & 39.19 & 39.63 \\
\hline Newfoundland & 1.72 & 1.61 & 1.28 & .68 \\
\hline PEI & .45 & .37 & .31 & .33 \\
\hline Nova Scotia & 3.26 & 2.66 & 2.58 & 2.28 \\
\hline New Brunswick & 2.22 & 2.18 & 1.81 & 1.72 \\
\hline Quebec & 27.48 & 26.99 & 28.17 & 24.61 \\
\hline Manitoba & 3.38 & 3.11 & 3.45 & 4.05 \\
\hline Saskatchewan & 2.81 & 3.12 & 3.37 & 4.75 \\
\hline Alberta & 9.37 & 8.83 & 7.38 & 7.13 \\
\hline $\mathrm{BC}$ & 13.90 & 13.44 & 12.46 & 14.82 \\
\hline Renter, \% & 18.67 & 18.52 & 21.87 & 31.81 \\
\hline Number of Observations & 4061 & 3747 & 3262 & 2538 \\
\hline
\end{tabular}

In each analysis, home ownership is used as the reference category of the dependent variable. Therefore, the odds ratios listed in Table 5 are the odds of living as a tenant, relative to owning a home, after taking into account the effects of all of the other variables in the model. Odds ratios greater than 1.00 indicate an increased likelihood of tenancy, whereas odds ratios less than 1.00 indicate a decreased likelihood.

Focusing on the effects of the sociodemographic control variables on the likelihood of tenancy (Model 1), Canadians are more likely to be tenants if they have lower levels of educational attainment $(\mathrm{OR}=1.147 ; \mathrm{p}=.000)$, are over the age of 75 $(\mathrm{OR}=1.103 ; \mathrm{p}=.000)$, are female $(\mathrm{OR}=1.037 ; \mathrm{p}=.000)$, and are living in an urban environment $(\mathrm{OR}=0.857 ; \mathrm{p}=.000)$. Relative to native-born Canadians, recent immigrants to Canada (post-1990) are more likely to be tenants $(\mathrm{OR}=1.178, \mathrm{p}=.000)$, whereas more established immigrants (pre-1990) are less likely to do so $(\mathrm{OR}=0.963$, $\mathrm{p}=.003$ ). Provincially, relative to Ontario, tenancy is less prominent among adults living in Newfoundland $(\mathrm{OR}=0.941 ; \mathrm{p}=.001)$, Manitoba $(\mathrm{OR}=0.953 ; \mathrm{p}=.003)$, Saskatchewan $(\mathrm{OR}=0.959 ; \mathrm{p}=.008)$, Alberta $(\mathrm{OR}=0.927 ; \mathrm{p}=.000)$, and $\mathrm{BC}(\mathrm{OR}=.972$; $\mathrm{p}=.028)$, more prominent in Quebec $(\mathrm{OR}=1.089 ; \mathrm{p}=.000)$, and neither more nor less prominent in PEI, Nova Scotia, and New Brunswick. 
Table 5: Logistic Regression Analyses of Predictors of Tenancy (vs. Home Ownership) among Canadians Age 45 and Older, 2002 General Social Survey

\begin{tabular}{|c|c|c|c|c|c|c|c|c|c|c|}
\hline \multirow[b]{3}{*}{ Partner is present } & \multicolumn{2}{|c|}{ Model 1} & \multicolumn{2}{|c|}{ Model 2} & \multicolumn{2}{|c|}{ Model 3} & \multicolumn{2}{|c|}{ Model 4} & \multicolumn{2}{|c|}{ Model 5} \\
\hline & OR & Sig. & $O R$ & Sig. & $O R$ & Sig. & $O R$ & Sig. & $O R$ & Sig. \\
\hline & - & - & .739 & .000 & - & - & - & - & .743 & .000 \\
\hline Age diff. between part. & - & - & 1.003 & .012 & - & - & - & - & 1.003 & .004 \\
\hline Number of children & - & - & 1.003 & .350 & - & - & - & - & 1.001 & .764 \\
\hline Number of siblings & - & - & 1.001 & .386 & - & - & - & - & 1.001 & .561 \\
\hline HUI & - & - & - & - & .850 & .000 & - & - & .906 & .000 \\
\hline Sometimes active & - & - & - & - & 1.015 & .207 & - & - & 1.020 & .059 \\
\hline Never active & - & - & - & - & 1.041 & .000 & - & - & 1.035 & .000 \\
\hline Excellent health & - & - & - & - & .978 & .571 & - & - & 1.007 & .589 \\
\hline Very good health & - & - & - & - & .964 & .295 & - & - & .996 & .820 \\
\hline Good health & - & - & - & - & .980 & .676 & - & - & .998 & .747 \\
\hline Fair health & - & - & - & - & 1.019 & .426 & - & - & 1.017 & .481 \\
\hline Income (logged) & - & - & - & - & - & - & .958 & .000 & .956 & .000 \\
\hline Works part-time & - & - & - & - & - & - & .916 & .000 & .977 & .229 \\
\hline Works & - & - & - & - & - & - & .937 & .000 & .981 & .405 \\
\hline Retir & - & - & - & - & - & - & .922 & .000 & .947 & .009 \\
\hline Years retired (logged) & - & - & - & - & - & - & 1.020 & .010 & 1.014 & .073 \\
\hline Elen & 1.147 & .000 & 1.130 & .000 & 1.112 & .000 & 1.094 & .000 & 1.065 & .000 \\
\hline $\mathrm{Higl}$ & 1.073 & .000 & 1.076 & .000 & 1.062 & .000 & 1.042 & .004 & 1.040 & .004 \\
\hline Son & 1.088 & .000 & 1.078 & .000 & 1.068 & .000 & 1.061 & .000 & 1.043 & .005 \\
\hline & 1.058 & .000 & 1.061 & .000 & 1.044 & .001 & 1.034 & .007 & 1.031 & .012 \\
\hline 55 & .996 & .630 & .993 & .464 & .989 & .291 & .983 & .098 & .982 & .123 \\
\hline $65-74$ & 1.009 & .424 & .986 & .240 & 1.003 & .706 & .972 & .055 & .970 & .124 \\
\hline $75+$ years & 1.103 & .000 & 1.014 & .554 & 1.077 & .000 & 1.045 & .142 & .981 & .318 \\
\hline Female & 1.037 & .000 & .993 & .240 & 1.033 & .000 & 1.008 & .345 & .965 & .000 \\
\hline Immigrated pre-1990 & .963 & .003 & .974 & .018 & .964 & .002 & .963 & .003 & .972 & .012 \\
\hline Immigrated post-1990 & 1.178 & .000 & 1.201 & .000 & 1.174 & .000 & 1.143 & .000 & 1.162 & .000 \\
\hline Rural & .857 & .000 & .876 & .000 & .858 & .000 & .855 & .000 & .873 & .000 \\
\hline Newfoundland & .941 & .001 & .942 & .001 & .940 & .001 & .927 & .000 & .929 & .000 \\
\hline PEI & 1.017 & .440 & 1.010 & .610 & 1.019 & .412 & 1.012 & .485 & 1.004 & .678 \\
\hline Nova Scotia & .988 & .442 & .985 & .239 & .982 & .269 & .980 & .278 & .972 & .083 \\
\hline New Brunswick & .973 & .147 & .967 & .055 & .968 & .117 & .962 & .073 & .954 & .019 \\
\hline Quebec & 1.089 & .000 & 1.071 & .000 & 1.091 & .000 & 1.079 & .000 & 1.063 & .000 \\
\hline Manitoba & .953 & .003 & .958 & .006 & .951 & .001 & .950 & .002 & .953 & .002 \\
\hline Saskatchewan & .959 & .008 & .960 & .012 & .960 & .006 & .961 & .009 & .961 & .008 \\
\hline Alberta & .927 & .000 & .925 & .000 & .928 & .000 & .929 & .000 & .926 & .000 \\
\hline $\mathrm{BC}$ & .972 & .028 & .967 & .006 & .972 & .023 & .971 & .027 & .965 & .006 \\
\hline Model fit (BIC) & -1272 & 269.00 & -1274 & 467.60 & $\mid-12723$ & 32.80 & -1272 & 50.30 & -1273 & 390.60 \\
\hline
\end{tabular}

Turning to the set of social support variables, Model 2 indicates that two of the four of these variables are significant predictors of tenancy. Namely, not having a partner present $(\mathrm{OR}=0.739 ; \mathrm{p}=.000)$ and a difference in age between partners 
$(\mathrm{OR}=1.003 ; \mathrm{p}=.012)$ are both associated with an increased likelihood of tenancy. In contrast, number of children and number of siblings are not significant predictors of tenancy.

Model 3 examines the set of health status variables. Based on the table, we see that lower scores on the HUI (i.e., poorer health) $(\mathrm{OR}=0.850 ; \mathrm{p}=.000)$ and lower levels of physical activity $(\mathrm{OR}=1.041 ; \mathrm{p}=.000)$ are both associated with an increased likelihood of tenancy. At the same time, none of the self-rated health dummies is significantly related to tenancy. ${ }^{10}$

Model 4 looks at the set of economic and labour force variables as potential predictors of tenancy. As the table shows, all of these variables are associated with tenancy. Specifically, higher income $(\mathrm{OR}=0.958 ; \mathrm{p}=.000)$, working either part-time $(\mathrm{OR}=0.916, \mathrm{p}=.000)$ or full-time $(\mathrm{OR}=0.937 ; \mathrm{p}=.000)$ and being retired $(\mathrm{OR}=0.922$; $\mathrm{p}=.000)$ are all associated with a decreased likelihood of tenancy. However, among retirees, as years since retirement increase, the probability of living as a tenant does as well $(\mathrm{OR}=1.020 ; \mathrm{p}=.010)$. This suggests that while tenancy is less likely at the point of retirement, the likelihood of tenancy increases the longer someone is retired.

In the fully controlled model (Model 5), there is relatively little change in the odds ratios associated with the blocks of predictor variables in the previous three models. However, working status and years since retirement are no longer significant predictors of tenancy in the fully controlled model. Therefore, overall, among the primary predictor variables, an increased likelihood of tenancy is associated with not having a partner present, an age difference between partners, poorer health, being inactive, having a lower income, and not being retired.

In addition to the odds ratios, model fit statistics are presented at the bottom of Table 5. Here we employ the Bayesian Information Criterion (BIC) to assess model fit. Generally, models with lower values of BIC are preferred, since lower values suggest a closer correspondence between the observed data and the experimental model, while penalizing for model complexity (Raftery, 1995). As Table 5 shows, the addition of the social support variables significantly improves model fit $(\mathrm{BIC}=-127467.6)$. In contrast, the inclusion of the health status variables in Model $3(\mathrm{BIC}=-127232.8)$ and the economic and labour force variables in Model $4(B I C=-127250.3)$ do not significantly improve the fit of the model over Model 1 . Therefore, while many of the variables that were added in Models 3 and 4 are statistically significant, they do not add much to the explanatory power of the model over and above that which is explained by the control variables and the social support characteristics presented in Model 2. ${ }^{11}$

10. An additional analysis of this model (not shown) with the HUI excluded showed that the self-rated health effect is being suppressed by the inclusion of the HUI in the model. When HUI was excluded a similar pattern emerged in which poorer self-rated health was associated with an increased likelihood of tenancy.

11. In preliminary analyses (not shown) we examined Model 2, 3, 4, and 5 with the control variables entered after the inclusion of the social support, health status, and economic and labour force variables rather than before. In each case, the model fit was significantly improved with the addition of the control variables. 


\section{Discussion and Conclusion}

Our analysis has considered hypotheses for three relationships: (1) that a strong social support network will be negatively associated with tenancy; (2) that healthy and physically fit individuals will be more likely to own their homes; and (3) that elevated wealth and/or economic status should prevent tenancy. The findings here are generally consistent with these three broad working hypotheses, but some qualifications are required, so we will deal with each hypothesis separately.

First, of the three hypotheses, we found the most support for the proposition that social support was negatively associated with tenancy. Specifically, as expected, older adults with a partner present were more likely than those without a partner present to live in a residence that they owned. This is consistent with the US research highlighted earlier in the literature review, and with findings for younger Canadians (Haan, 2005b; Skaburskis, 1997). As expected, a positive age difference (meaning that the partner is older than the respondent) between partners is associated with a greater likelihood of tenancy. This is not surprising, given that smaller or negative age gaps between partners have the potential to increase the capacity for an individual to receive care from his/her spouse, thereby decreasing the need to move into alternative care-related residential options (e.g., a retirement home). Additionally, contrary to our expectations, number of children and number of siblings made no difference to the likelihood of tenancy. Looking into the future, this suggests that it is unlikely that the lower fertility rates of today, relative to the past, will have an impact on the future tenancy rates of Canadians as they age.

There is also some evidence, as expected, that poor health and limited physical activity predicts tenancy. This finding is consistent with research conducted in the US showing that declines in health or physical status often result in a change in residential status. In terms of tenancy rates in the future, given the steady increases in the health status of older Canadians relative to previous generations, we might speculate that tenancy rates may decrease among this group in the coming years, and that home ownership rates, relative to today, will increase. Somewhat surprisingly, however, the inclusion of these variables were not worthwhile in terms of model fit, suggesting that on average numerous other factors are probably more powerful as predictors.

Although they did not have the expected impact, our findings for the economic and labour force variables are, for the most part, expected. Income, employment status, and retirement status are all positively related to the likelihood of living in a private dwelling. This positive finding for retirement status was contrary to our expectations, however. At the same time, the longer individuals were retired, the more likely they were to live in a non-private dwelling. One interpretation of this finding is that older adults, upon retirement, can afford to live in a private dwelling, but over time must adjust to the demands of having a lower income by liquidating this particular source of wealth as they age. These changes don't appear to begin to 
occur until at least age 65 , suggesting that future studies could eliminate earlier age groups.

Overall, our findings are generally consistent with the US literature. However, the research reported here extends the findings of this previous US literature to the Canadian population, and advances the literature by evaluating the comparative impact of several sets of characteristics on housing tenure status. These findings are particularly useful, given the lack of Canadian studies on predictors of dwelling choice.

Additionally, these findings suggest that the microeconomic model of consumer choice might be somewhat limited and simplistic for understanding the tenure choices of older Canadians. Notably, although several economic and labour market characteristics were significant predictors of tenancy, what is interesting is that the comparative impact of these variables was small, relative to changes in social support status. Although this cannot be confirmed with cross-sectional data, the results presented here tentatively suggest that individuals are more likely to move out of home ownership due to changes in social support characteristics than they are due to changes in economic or health characteristics. Of course, this suggestion is difficult to evaluate with cross-sectional data, so it should be seen as tentative, and our findings should be read with this in mind. Health and economic factors might matter more in an environment where old-age economic security is more precarious, and there is no universal healthcare system, although once again this is difficult to determine in the present study. Given the weak connection between health and economic characteristics and housing tenure, however, this study suggests that there may be significant deviations from the pathway predicted by the housing career (see also Ostrovksy and Crossley, 2003 for discussion of this).

It is important to restate that our findings here are somewhat limited in that they are based on cross-sectional data. Data that are either a repeated cross-section (GSS16 is the first survey of older Canadians in Canada) or longitudinal, and which collect information on the sociodemographic, social support, health, economic, and housing characteristics over many years would be beneficial for understanding the housing careers of older Canadians. Unfortunately, we are still many years away from such data being available in Canada.

On a concluding note, while there is certainly more to be done, this report provides a "first look" into the housing tenure patterns of older Canadians. Research currently underway by the authors will further develop this line of inquiry by projecting demand for several residential types (living in a dwelling without a minimum age requirement, a dwelling with a minimum age requirement but no available nursing care, a dwelling with a minimum age requirement and available nursing care) into the future. Given the aging baby boomer population, there is a need to continue to develop our understanding of the interplay between changing characteristics of aging Canadians and their housing tenure, while we await data with a temporal component to allow for a more detailed exploration of the predictors of dwelling choice. 


\section{Acknowledgements}

The authors wish to thank Rod Beaujot, Susan McDaniel, Zenaida Ravanera, John Rietschlin, and Andrew Wister for reading over earlier drafts of this paper, and/or helping to develop the ideas herein. Thanks to Human Resources and Social Development Canada for funding a follow-up study of this topic. All errors and omissions are the responsibility of the authors.

\section{References}

Alba, R.D. and J. Logan. 1992. "Assimilation and stratification in the homeownership patterns of racial and ethnic groups.” International Migration Review 26(4):1314-1341.

Andersen, R.T., M.K. James, M.E. Miller, A.S. Worley, and C.E. Longino. 1998. "The timing of change: Patterns in transitions in functional status among elderly person." Journals of Gerontology, Series B: Psychological Sciences and Social Sciences 53:S17-S27.

Balakrishnan, T.R. and Z. Wu. 1992. "Home ownership patterns and ethnicity in selected Canadian cities." Canadian Journal of Sociology/Cahiers canadiens de sociologie 17(4):389-403.

Beaujot, R.P. 2004. Delayed Life Transitions: Trends and Implications. Ottawa: Vanier Institute of the Family.

Bowlby, G. 2007. "Defining retirement.” Perspectives on Labour and Income 8:15-19.

Branch, L.G. and A.M. Jette. 1982. "A prospective study of long-term care institutionalization among the aged.” American Journal of Public Health 72(12):1373-1379.

Breeze, E., A. Sloggett, and A. Fletcher. 1999. "Socioeconomic and demographic patterns of mortality and institutional residence among middle aged and older people: Results from the longitudinal study." Journal of Epidemiology and Community Health 53:765-774.

Canada Mortgage and Housing Corporation. 1992. Housing an Aging Population: Guidelines for Development and Design (2nd ed.). Ottawa: CMHC.

2001. User Satisfaction Study of Housing Options for Older Canadians. Ottawa: CMHC.

Cheal, D. 2000. “Aging and demographic change." Canadian Public Policy 26(Supplement 2):S09-S122.

Crossley, T.F. and Y. Ostrovsky. 2003. A Synthetic Cohort Analysis of Canadian Housing Careers. Hamilton, ON: SEDAP, McMaster University.

Devereaux, M.S. 1990. "Decline in the number of children.” Canadian Social Trends 18:201-204.

Dunn, J.R., M.V. Hayes, J.D. Hulchanski, S.W. Hwang, and L. Potvin. 2006. "Housing as a socio-economic determinant of health: Findings of a national needs, gaps and opportunities assessment." Canadian Journal of Public Health 97:S11-S15.

Easterlin, R.A., C.M. Schaeffer, and D.J. Macunovich. 1993. "Will the baby boomers be less well off than their parents: Income, wealth, and family circumstances over the life cycle in the United States." Population and Development Review 19(3):497-522. 
Flippen, C.A. 2001. "Residential segregation and minority home ownership." Social Science Research 30(3):337-362.

Foot, D. and D. Stoffman. 1996. Boom, Bust and Echo. Toronto: Macfarlane, Walter, and Ross.

Foote, N.N., J. Abu-Lughod, M.M. Foley, and L. Winnick. 1960. Housing Choices and Constraints. New York: McGraw-Hill.

Haan, M. 2005a. Are Immigrants Buying to Get In? The Role of Ethnic Clustering on the Homeownership Propensities of 12 Toronto Immigrant Groups, 1996-2001. Ottawa: Statistics Canada.

2005b. "The decline of the immigrant homeownership advantage: Life-cycle, declining fortunes and changing housing careers in Montreal, Toronto and Vancouver, 1981-2001." Urban Studies 42(12): $1-22$.

2007. "The homeownership hierarchies of Canada and the United States: The housing patterns of white and nonwhite immigrants of the past 30 years." International Migration Review 33(2):433465 .

- forthcoming. "Do I buy with a little help from my friends? Homeownership-relevant group characteristics and homeownership disparities among Canadian immigrant groups, 1971-2001." Housing Studies.

Hays, J.C. 2002. "Living arrangements and health status in later life: A review of recent literature." Public Health Nursing 19(2):136-151.

Hays, J.C. and L.K. George. 2002. "The life course trajectory toward living alone: Racial differences." Research on Aging 24:283-307.

Lakdawalla, D.N. and R.F. Schoeni. 2003. "Is nursing home demand affected by the decline in age difference between spouses?" Demographic Research 8(10):279-303.

Légaré, J. 1998. Living Arrangements of Older Persons in Canada: Effects on their Socio-economic Conditions. New York: United Nations and Statistics Canada.

Lin, J. 2005. "The housing transitions of seniors." Canadian Social Trends 11(8):22-28.

Martel, L. and A. Bélanger. 2002. Analysis of the Change in Dependence-free Life Expectancy in Canada Between 1986 and 1996. Ottawa, ON: Statistics Canada.

Mulder, C.H. 1993. Migration Dynamics: A Life Course Approach. Amsterdam: Thesis Publishers.

Murdie, R.A., A.S. Chambon, J.D. Hulchanski, and C. Teixeira. 1999. Differential Incorporation and Housing Trajectories of Recent Immigrant Households: Toward a Conceptual Framework. Toronto: Housing New Canadians Working Group.

Myers, D. and S.W. Lee. 1998. "Immigrant trajectories into homeownership: A temporal analysis of residential assimilation." International Migration Review 32(3):593-625.

Nagatani, K. 1972. "Life cycle saving: Theory and fact." American Economic Review 62:344-353.

National Advisory Council on Aging. 2006. Seniors in Canada: 2006 Report Card. Ottawa: Government of Canada National Advisory Council on Aging.

Pynoos, J. and S. Golant. 1996. Housing and living arrangements for the elderly. In R.H. Binstock and L.K. George, eds., Handbook of Aging in the Social Sciences. San Diego, CA: Academic Press.

Quadagno, J. 1980. Aging, the Individual, and Society. New York: St. Martin's Press. 
Raftery, A. 1995. Bayesian model selection in social research. In P.V. Marsden, ed., Sociological Methodology. Cambridge, MA: Blackwell.

Ravanera, Z.R., F. Rajulton, and T.K. Burch. 1998. "Early life transitions of Canadian women: A cohort analysis of timing sequences, and variations." European Journal of Population 14:179-204.

Ray, B.K. and E.G. Moore. 1991. "Access to home ownership among immigrant groups in Canada." Canadian Review of Sociology and Anthropology 28(1):1-29.

Roberge, R., J. Berthelot, and M. Wolfson. 1995. "The Health Utility Index: Measuring health differences in Ontario by socioeconomic status." Health Reports 7:25-32.

Schellenberg, G. 2004. The Retirement Plans and Expectations of Non-retired Canadians Aged 45 to 59. Ottawa: Statistics Canada.

Schellenberg, G., M. Turcotte, and B. Ram. 2005. "Preparing for retirement." Canadian Social Trends $78: 8-11$.

Skaburskis, A. 1996. "Race and tenure in Toronto." Urban Studies 33(2):223-252. - 1997. "Gender differences in housing demand." Urban Studies 34(2):275-320.

Smith, G. 1996. The Population in Collective Dwellings: Canada, 1971-1991. Ottawa: Statistics Canada.

Statistics Canada. 2002. General Social Survey Cycle 16: Aging and Social Support: User's Guide to the Public Use Microdata File. Ottawa: Statistics Canada.

2006. A Portrait of Seniors in Canada. Ottawa: Statistics Canada. 2007. "A portrait of seniors." The Daily February 27th: 5-6.

Tomassini, C., K. Glaser, D.A. Wolf, M.I. Broses, and E. Grundy. 2004. "Living arrangements among older people: An overview of trends in Europe and the USA." Population Trends 115(Spring):2-12.

Trottier, H., L. Martel, C. Houle, J. Berthelot, and J. Légaré. 2000. "Living in a home or in an institution: What makes the difference for seniors?" Health Reports 11:49-60.

United States Department of Housing and Urban Development Office of Policy Development and Research. 1999. Housing our Elders: A Report Card on the Housing Conditions and Needs of Older Americans. Washington, DC: United States Department of Housing and Urban Development Office of Policy Development and Research.

Wister, A.V. 2005. Baby Boomer Health Dynamics: How Are We Aging? Toronto: University of Toronto Press.

Wu, Z. 1998. "Recent trends in marriage patterns in Canada." Policy Options 19:3-6. 